\title{
Pengembangan E-PUB untuk Administrasi Sistem Jaringan
}

\author{
Chandra Setia Rini ${ }^{1}$, Nurmida Catherine Sitompul ${ }^{2}$, Yoso Wiyarno ${ }^{3}$ \\ ${ }^{1,2,3}$ Pascasarjana - Teknologi Pendidikan Universitas PGRI Adibuana Surabaya \\ ${ }^{1}$ Guru SMK Negeri 1 Gempol Pasuruan Jawa Timur
}

\section{Edcomtech}

\section{Jurnal Kajian}

Teknologi Pendidikan

Volume 6, No 1, April 2021

89-99

Submitted 09-03-2020

Accepted 14-04-2020

Corresponding Author

Chandra Seti Rini

chandragreena211@gmail.com

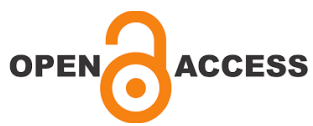

\begin{abstract}
Abstrak
Pembelajaran di SMK merupakan pendidikan vokasi memiliki karakteristik tersendiri. Mata pelajaran Adminsitrasi Sistem Jaringan (ASJ) pada kompetensi keahlian Teknik Komputer dan Jaringan (TKJ) mempelajari tentang prosedur bagaimana sebuah komputer dapat berperan menjadi server sehingga membutuhkan ketelitian untuk melakukan konfigurasi layanan jaringan yang sesuai prosedur. Tujuan penelitian ini menemukan efektifitas pengembangan buku digital ePub sebagai bahan ajar pendamping dalam proses pembelajaran. Pengembangan buku digital ePub menggunakan model ADDIE dengan teknik analisis data bersifat deskriptif. Hasil validasi kelayakan produk pengembangan yaitu ahli isi/materi TKJ sebesar 90,67\%, ahli media pembelajaran sebesar 90,52\%, dan ahli desain pembelajaran sebesar 96\%. Evaluasi produk kepada pengguna (siswa) melalui angket mendapatkan respon yang sangat baik. Uji coba produk yang telah dilakukan dapat meningkatkan efektifitas pembelajaran dengan meningkatnya nilai tes akhir siswa. Sehingga dapat disimpulkan bahwa produk yang telah dikembangkan layak digunakan dalam pembelajaran Administrasi Sistem Jaringan.
\end{abstract}

Kata kunci: buku digital , ePub, pendidikan vokasi, administrasi sistem jaringan

\begin{abstract}
Learning in vocational schools is a vocational education has its own characteristics. Network System Administration (ASJ) subjects in Computer and Network Engineering (TKJ) competencies learn about procedures how a computer can act as a server so it requires accuracy to configure network services according to procedure. The purpose of this study is to find the effectiveness of ePub digital book development as a teaching material in the learning process. Development of ePub digital books using ADDIE models with descriptive data analysis techniques. The results of the or validation of the feasibility of product development are content experts / TKJ by $90.67 \%$, learning media experts by $90.52 \%$, and learning design experts by $96 \%$. Product evaluations to users (students) through a questionnaire get a very good response. Product trials that have been carried out can increase the effectiveness of learning by increasing student final test scores. So it can be concluded that the product that has been developed is feasible to use in learning Network Administration System.
\end{abstract}

Keywords: digital books, ePub, vocational education, network system administration 


\section{LATAR BELAKANG}

Kebijakan Nasional menyatakan bahwa perancangan kurikulum disesuaikan dengan kebutuhan pada saat ini dan untuk masa yang akan datang. Kurikulum diharapkan dapat membantu perkembangan siswa dalam kemampuan berbahasa inggris, kemampuan dalam mengikuti perkembangan ICT yang semakin pesat, dan perkembangan dalam berprilaku baik dan berpikir kritis. Namun masih ada beberapa SMK yang kondisi siswanya kurang dalam memahami dan menyerap pelajaran dengan baik. Faktor yang mempengaruhi kurangnya pemahaman siswa terhadap materi pelajaran salah satunya yaitu proses belajar dilakukan hanya pada saat kegiatan pembelajaran di sekolah, tanpa ditindaklanjuti dengan belajar di rumah. Hal ini terjadi karena media pembelajaran yang digunakan tidak dapat dimanfaatkan siswa untuk belajar secara mandiri di luar jam belajar di sekolah. Sehingga mengurangi minat dan motivasi siswa untuk belajar dan mengulang lagi pelajaran secara mandiri di rumah. Siswa pada pendidikan kejuruan mempunyai karakteristik yang berbeda dibandingkan dengan siswa di bidang pendidikan lainya, karena orientasi belajar siswa SMK lebih fokus pada pekerjaan sesuai dengan program keahliannya.

Generasi muda di abad 21 harus didukung dengan hal-hal baru seperti penggunaan e-book dalam menumbuhkan motivasi belajar selama proses pembelajaran (Bau, Sunardi, \& Sudiyanto, 2017). Dunia pendidikan pada abad 21 ini dituntut agar mampu mencetak siswa yang mempunyai keterampilan belajar dan berinovasi, keterampilan menggunakan teknologi dan dapat bekerja dengan life skills yang dimiliki (Anggraeni \& Sole, 2018). Teknologi dapat membantu dalam meningkatkan kualitas pengajaran. Guru dengan menggunakan perangkat modern atau gadget, dapat membuat standar pengajaran mereka efektif dan up-to-date di zaman modern saat ini (Irum, Munshi, Bhatti, \& Awan, 2018). Pentingnya merancang pembelajaran yang terintegrasi dengan IT bagi guru adalah untuk mencapai tujuan pembelajaran yang efektif dan efisien (Wardani, Rufi'i, \& Harwanto, 2019).
Siswa di abad 21 ini merupakan generasi digital dimana perangkat seluler, smartphone, dan tablet sudah tersedia secara luas. Sehingga sistem pembelajarannya harus dirancang tidak lagi secara tradisional (Figueiredo, Bidarra, \& Bostad, 2016). Sebuah tantangan dalam kebiasaan sehari-hari dan cenderung sulit dipisahkan dalam kehidupan masyarakat dari segala usia yaitu penggunaan smartphone khususnya pada siswa sekolah menengah atas atau kejuruan (Ningsih \& Adesti, 2019). Teknologi informasi dan komunikasi dapat dikatakan sebagai gudang pengetahuan, sumber belajar bahkan sebagai fasilitas Pendidikan, sehingga guru hendaknya mengikuti perkembangan teknologi yang ada (Purnamawati, Arfandi, \& Nurfaeda, 2019).

Bahan ajar merupakan semua bentuk bahan yang digunakan untuk membantu guru dalam melaksanakan kegiatan pembelajaran. Dan juga merupakan suatu alat penting yang dibutuhkan dalam proses pembelajaran untuk mempermudah siswa dalam memahami dan mempelajari suatu materi tertentu (Mardiyah, Mustaji, \& Sitompul, 2019; Surahman et al., 2020). Guru menggunakan TIK untuk membuat proses belajar mengajar mudah dan menarik. Seorang guru yang kompeten memiliki beberapa keterampilan dan teknik untuk memberikan pengajaran yang sukses (Bhattacharjee \& Deb, 2016). Bahan ajar adalah salah satu bagian dari sumber ajar yang mengandung pesan pembelajaran, baik yang bersifat khusus maupun umum yang dapat dimanfaatkan untuk pembelajaran, dalam Mulyasa (2013:96). Dalam pengembangan bahan ajar harus menggunakan model pengembangan tertentu agar mendapat kualitas pembelajaran yang baik. Merancang bahan ajar dengan baik dapat meningkatkan hasil belajar.

Pendidikan menengah kejuruan merupakan pendidikan vokasi yang mengutamakan pada penguasaan keahlian tertentu. SMK bertujuan menyiapkan siswa dalam menghadapi lapangan kerja dan mempunyai sikap profesional dalam bekerja di Dunia Usaha / Dunia Industri (DU/DI). Menurut Peraturan Pemerintah Nomor 29 Tahun 1990 bahwa sesuai bentuknya, sekolah menengah kejuruan menyelenggarakan program- 
program pendidikan yang disesuaikan dengan jenis-jenis lapangan kerja.

SMK mempunyai banyak program keahlian. Pelaksanaan dalam pemilihan program keahlian disesuaikan dengan dengan kebutuhan di DU/DI. Teknik Komputer dan Jaringan (TKJ) merupakan salah satu program keahlian di SMK. Struktur Kurikulum Kompetensi Keahlian TKJ telah mengalami beberapa kali perubahan, dari Kurikulum Tingkat Satuan Pendidikan (KTSP), kemudian Kurikulum 2013, Kurikulum 2013 Revisi 2016 dan revisi terakhir Kurikulum 2013 yang direvisi pada tahun 2017.

Dampak dari perubahan kurikulum ini ada beberapa mata pelajaran yang di gabung menjadi satu mata pelajaran. Salah satu contohnya yaitu mata pelajaran Sistem Operasi Jaringan dan Administrasi Server digabung menjadi satu mata pelajaran Administrasi Sistem Jaringan (ASJ). Untuk mata pelajaran ASJ belum ada buku digital yang dibuat. Beberapa penerbit telah menerbitkan bahan ajar berupa buku cetak dan belum dilengkapi dengan buku digital atau e-book. Administrasi Sistem Jaringan merupakan salah satu kompetensi yang harus dimiliki oleh siswa SMK pada program keahlian TKJ. Siswa diharapkan mampu menjadi seorang administrator jaringan komputer khususnya pada komputer yang bertindak sebagai PC Server . Tugas seorang administrator jaringan komputer meliputi instalasi sistem operasi jaringan dan melakukan konfigurasi layananlayanan yang ada di server sebagai sumber daya untuk client yang terhubung ke server. Sebagian besar SMK di Indonesia mempunyai jumlah peserta didik kecil dan sedang. Media pembelajaran yang digunakan dalam pembelajaran belum mencukupi kebutuhan peserta didiknya.

Proses belajar mengajar di SMKN 1 Gempol, khususnya pada mata pelajaran Administrasi Sistem Jaringan yaitu guru memberikan materi berupa file presentasi (ppt) menggunakan LCD proyektor, kemudian memberikan panduan praktikum berupa jobsheet atau langkah kerja yang dicetak dan siswa memfotocopynya. Jika siswa mengalami kesulitan terkait pemahaman terhadap materi siswa mencari sumber belajar sendiri di internet. Sehingga perlu adanya pengembangan bahan ajar berupa buku digital yang dapat digunakan untuk menunjang proses belajar siswa, menarik minat belajar siswa terhadap pembelajaran, dan dapat digunakan secara mandiri. Pembelajaran menggunakan smartphone dapat terjadi karena tuntutan penggunaan smartphone yang semakin canggih dan belum banyak digunakan dalam bidang pendidikan. Selain itu, harga smartphone lebih murah dibandingkan dengan laptop atau PC (Syaimar \& Sutiarso, 2017).

Buku cetak sebagai buku pendamping proses belajar siswa tersedia di perpustakaan, namun belum dilengkapi dengan panduan praktikum dan video pembelajaran. Dalam sebuah bahan ajar gambar dan teks saja belum cukup dalam penyampaian materi kepada siswa (Purba, Liliana, \& Runtulalu, 2017). Sedangkan di SMK khususnya pada Kompetensi Keahlian TKJ banyak materi yang mengharuskan peserta didik melakukan praktikum. Pada mata pelajaran Administrasi Sistem Jaringan membutuhkan waktu 6 JP ( 45 menit x 6 ) tiap tatap muka. Selama 6 JP tersebut terdapat teori dan praktek. Dengan buku digital electronic publication (Epub) yang dilengkapi dengan panduan praktikum diharapkan dapat membantu dalam proses pembelajaran, sehingga guru dan peserta didik dapat memanfaatkan waktu untuk teori dan praktek secara efektif dan efisien. Epub dapat digunakan dengan menggunakan laptop dan smartphone. Pembelajaran mobile adalah penyatuan teknologi komputasi mobile dan e-learning dalam bidang TIK yang berkembang sangat pesat. Jenis lingkungan belajar ini memungkinkan peserta didik untuk mengakses materi pembelajaran dari mana saja kapan saja (Vinu, Sherimon, \& Krishnan, 2011).

Sarana yang ada di SMKN 1 Gempol sendiri telah tersedia Lab. Komputer dan akses internet yang cukup memadai yang dapat digunakan untuk proses pembelajaran. Dan sekitar 20 siswa dari 36 siswa telah memiliki laptop sendiri, serta $100 \%$ siswa mempunyai smartphone android. Sehingga sarana untuk mengembangkan buku digital electronic publication (Epub) sangat mungkin 
dilakukan. Dengan menggunakan buku digital dapat mengurangi penggunaan kertas dan mendukung gerakan paperless.

SMKN 1 Gempol merupakan salah satu sekolah yang berbasis IT. Dimulai dari kegiatan Ulangan Harian (UH), Penilaian Tengah Semester (PTS) dan Penilaian Akhir Semester (PAS) telah menggunakan sistem berbasis online, dimana siswa bisa menggunakan laptop maupun smartphone android untuk mengerjakan soal-soal. Bahan ajar yang digunakan dalam pembelajaran diantaranya buku teks, power point, video pembelajaran, modul dan lembar kerja siswa. Bahan ajar tersebut kurang praktis karena tidak bisa digunakan secara mandiri oleh siswa. Buku-buku yang telah disediakan di perpustakaan, juga kurang diminati siswa. Hal ini disebabkan kurangnya minat baca dan juga memerlukan waktu khusus untuk membaca di perpustakaan.

Berdasarkan kondisi yang telah diuraikan diatas memperlihatkan bahwa diperlukannya pengembangan bahan ajar pendamping yang berupa buku digital electronic publication (Epub) yang mempunyai daya tarik agar siswa rajin belajar, lebih mudah memahami materi pelajaran dan dapat dipelajari dimana saja dengan menggunakan laptop maupun smartphone.

\section{METODE}

Dalam pengembangan buku digital electronic publication (ePub) ini menggunakan model ADDIE (Analysis, Design, Development, Implementation, dan Evaluation).

Prosedur pengembangan

ADDIE merupakan proses siklus yang berkembang dari waktu ke waktu dan berkesinambungan dari seluruh perencanaan dan proses implementasinya (Kurt, 2017). Dari kelima tahapan memiliki kerangka kerja masingmasing dengan tujuan yang berbeda dan fungsi dalam perkembangan desain instruksional.

\section{Tahapan Pengembangan}

\section{Analyze (Analisis)}

Pada tahap ini peneliti menganalisis perlunya pengembangan bahan ajar sebagai pedoman dan pertimbangan dalam penyusunan buku digital. Analisis yang dilakukan yaitu 1) Analisis Kebutuhan (need assessment) yaitu peneliti menganalisis keadaan bahan ajar yang digunakan dalam pembelajaran dan ketersediaan bahan ajar yang mendukung pembelajaran. Kemudian akan ditentukan bahan ajar yang dapat membantu peserta didik dalam belajar. 2) Analisis Kurikulum yaitu untuk mengetahui karakteristik kurikulum yang sedang digunakan di sekolah. Hal ini dilakukan agar pengembangan yang dilakukan dapat sesuai dengan kurikulum yang berlaku. Kemudian peneliti mengkaji Kompetensi Dasar yang digunakan untuk merumuskan indikatorindikator dalam pencapaian pembelajaran.

\section{Design (Rancangan)}

Pada tahap ini mulai dirancang buku digital berbasis electronic publication (ePub) yang disesuaikan dengan hasil analisis yang dilakukan sebelumnya. Selanjutnya, peneliti menentukan unsur - unsur yang diperlukan dalam buku digital ePub seperti penyusunan peta kebutuhan dan kerangka buku digital. Referensi yang akan digunakan dalam mengembangkan materi dalam buku digital dikumpulkan untuk menyusun isi atau materi sesuai dengan kompetensi dasar yang telah di kaji pada tahap sebelumnya.

\section{Development (Pengembangan)}

Tahap pengembangan yaitu proses mewujudkan rancangan atau desain menjadi kenyataan. Pada tahap ini dikembangkan buku digital dengan format file electronic publication (ePub) dengan menggunakan software editor Sigil. Aplikasi Sigil ini merupakan perantara / penghubung agar buku digital dengan format ePub dapat digunakan pada smartphone dan laptop ((Darma, Setyadi, Wilujeng, Jumadi, \& Kuswanto, 2019).

\section{Implementation (Implementasi)}

Pada tahap implementasi buku digital ePub yang telah dikembangkan di-instal dan di-setting pada laptop maupun smartphone agar dapat diimplementasikan untuk dilakukan review ahli.

\section{Evaluation (Evaluasi)}

Pada tahap evaluasi ini peneliti 
melakukan evaluasi terhadap hasil pengembangan buku digital ePub dengan menggunakan evaluasi formatif (Tessmer).

\section{Subjek Pengembangan}

Validasi produk dilakukan oleh 1) Ahli Isi/ materi mata pelajaran Administrasi Sistem Jaringan yaitu dosen Prodi Teknik Informatika Universitas Yudharta Pasuruan yang memiliki keahlian dalam bidang Teknik Komputer dan Jaringan, 2) Ahli Media pembelajaran yaitu dosen dosen FKIP Universitas PGRI Adi Buana Surabaya merupakan ahli di bidang media pembelajaran, 3) Ahli Desain pembelajaran yaitu dosen Magister Teknologi Pendidikan Universitas PGRI Adi Buana Surabaya merupakan ahli di bidang desain pembelajaran bertujuan untuk mendapat penilaian terhadap desain produk. Evaluasi terhadap produk dilakukan oleh pengguna buku digital e-Pub yaitu siswa kelas XI Kompetensi Keahlian Teknik Komputer dan Jaringan di SMKN 1 Gempol sebanyak 35 siswa dalam satu kelas.

\section{Teknik Pengumpulan Data}

Teknik pengumpulan data yang digunakan dalam penelitian ini yaitu dengan memberikan angket kepada responden. Menurut Sugiyono (2015:199), dengan menggunakan angket adalah teknik pengumpulan data yang dilakukan dengan memberikan pertanyaan atau pernyataan tertulis kepada responden untuk dijawab. Semua data yang terkumpul dari angket yang diberikan kepada ahli materi, ahli desain, ahli media, dan pengguna kemudian dianalisis. Teknik analisis data yang dilakukan menggunakan pengukuran dengan skala Likert 5 poin dengan skor setiap jawaban pada angket yaitu sangat layak (5), layak (4), cukup (3), tidak layak (2), dan sangat tidak layak (1). Untuk menganalisis data kuantitatif yaitu berupa skor angket penilaian yang diberikan pada subjek, dengan menghitung persentase jawaban kemudian dihitung dengan rumus Persentase untuk mengetahui tingkat kelayakan produk dilihat dari sudut pandang pengguna.

$$
\text { Persentase Kelayakan }(\%)=\frac{\text { skor observasi }}{\text { skor maksimal }} \times 100 \%
$$

Data yang sudah dihitung dengan rumus Persentase kemudian dikonversi berdasarkan tabel kategori kelayakan seperti table berikut ini

\section{Tabel 1. Skala Persentase Kelayakan}

\begin{tabular}{ll}
\hline Angka (\%) & Klarifikasi \\
$<21$ & Sangat Tidak Layak \\
$\mathbf{2 1 - 4 0}$ & Tidak Layak \\
$\mathbf{4 1 - 6 0}$ & Cukup \\
$\mathbf{6 1 - 8 0}$ & Layak \\
$\mathbf{8 1 - 1 0 0}$ & Sangat Layak
\end{tabular}

\section{HASIL DAN PEMBAHASAN}

Hasil penelitian pada Tahap Analisis (Analyze) yaitu terdiri dari analisis kebutuhan (need assessment) dan analisis kurikulum. Hasil analisis kebutuhan yang dilakukan peneliti dengan mewawancarai siswa kelas XI TKJ di SMK Negeri 1 Gempol dan menghasilkan data analisis sebagai berikut: 1) Bahan ajar yang digunakan untuk pembelajaran masih menggunakan buku teks, 2) Dengan bahan ajar yang ada, siswa masih kesulitan dalam memahami materi pelajaran, 3) Siswa juga masih kesulitan dalam menjawab pertanyaan evaluasi, 4) Menurut sebagian besar pendapat siswa, mereka lebih mudah memahami materi dengan belajar menggunakan laptop dan smartphone, 5)Buku digital (e-book) untuk pembelajaran administrasi sistem jaringan yang diharapkan siswa dilengkapi dengan teks, gambar dan video. Analisis Kurikulum dilakukan dengan observasi terhadap kurikulum yang digunakan. Kemudian peneliti menyusun Silabus disesuaikan dengan Kompetensi Dasar (KD) berdasarkan Kurikulum 2013 Revisi 2017 Kompetensi Keahlian Teknik Komputer dan Jaringan.

Langkah berikutnya adalah Perancangan (Design). Pada tahap ini mulai dirancang buku digital berbasis electronic publication (ePub) dengan disesuaikan dari hasil analisis yang dilakukan pada tahap sebelumnya. Pada 
tahap desain yang telah dilakukan peneliti meliputi: 1)Menyiapkan buku referensi yang berkaitan dengan mata pelajaran Administrasi Sistem Jaringan, 2) Penyusunan kerangka buku digital electronic publication (e-Pub), 3) Pembuatan video yang berhubungan dengan materi, 4) Penyusunan jobsheet, dan Menentukan bentuk evaluasi.

Langkah ketiga adalah Pengembangan (Development). Setelah terbentuknya rancangan, selanjutnya adalah pengembangan. Pada tahap pengembangan peneliti menyusun buku digital electronic publication (e-Pub) berdasarkan data-data yang telah diperoleh dari tahap sebelumnya. Pada tahap ini mencakup penulisan dan penyusunan materi, pemasangan gambar atau ilustrasi, penambahan video, visualisasi dan pembuatan perangkat evaluasi kemudian disimpan dengan ekstensi .epub. Produk ePub yang dihasilkan pada tahap ini terdiri atas tampilan awal (cover), pendahuluan, tujuan, materi, video, jobsheet, , evaluasi, kunci jawaban, daftar pustaka dan profil.

Langkah keempat yaitu Implementasi (Implementation). Review terhadap buku digital secara langsung dilakukan peneliti pada tahap ini. Review dilaksanakan melalui review oleh ahli isi / materi mata pelajaran, ahli desain pembelajaran, dan ahli desain pembelajaran. Dari hasil penelitian dijelaskan bahwa dari ahli isi/materi TKJ sebesar 90,67\%, ahli media pembelajaran sebesar $90,52 \%$, dan ahli desain pembelajaran sebesar $96 \%$ dengan kualifikasi sangat layak. Setelah dilakukan review ahli, peneliti merevisi produk sesuai dengan hasil review dari para ahli. Secara ringkas bagian bagian produk yang telah direvisi antara lain :

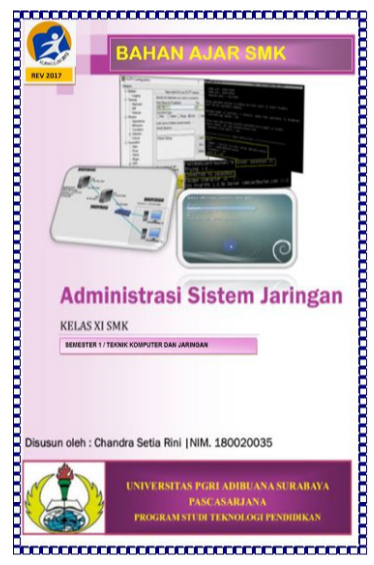

Gambar 1 Cover Yang telah Direvisi

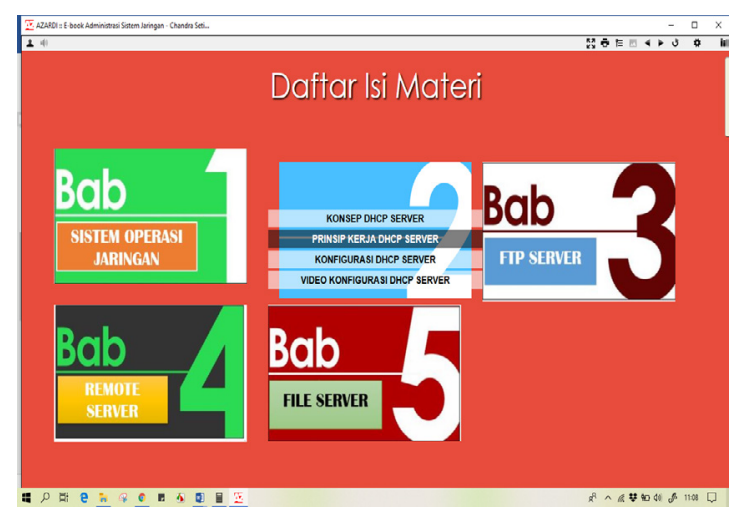

\section{Gambar 2 Daftar Isi Yang telah Direvisi}

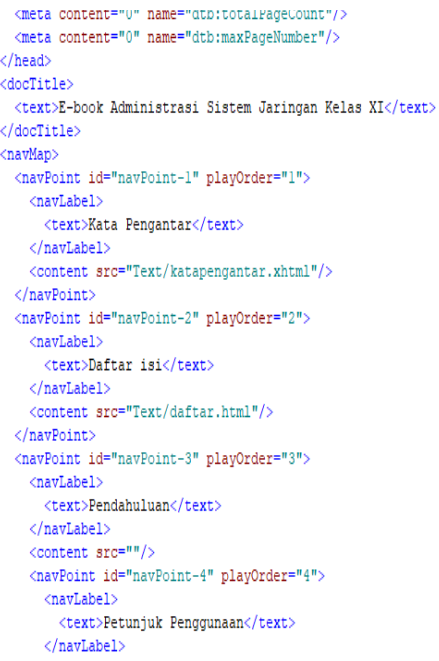

Gambar 3 Memperbaiki Coding Hyperlink

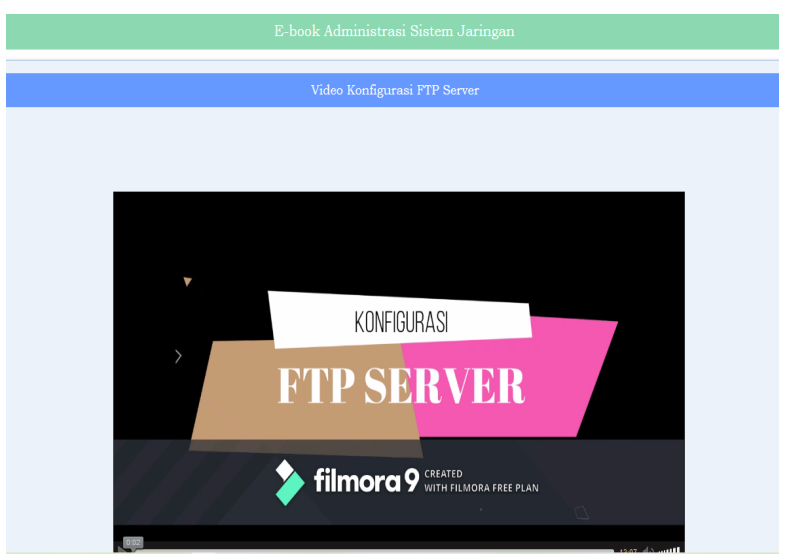

\section{Gambar 4 Materi dilengkapi dengan Video}

Langkah kelima yaitu Evaluasi (Evaluation). Pada tahap evaluasi ini peneliti melakukan evaluasi terhadap hasil pengembangan buku digital ePub dengan menggunakan evaluasi formatif (Tessmer). Trianto (2010:216) menyatakan bahwa melakukan evaluasi formatif dapat mengumpulkan data untuk mengetahui efektivitas dan efisiensi terkait 
produk yang dikembangkan untuk mencapai tujuan yang sudah ditentukan. Pada evaluasi formatif terdapat 4 tahap yaitu 1) expert review, 2) one-to-one evaluation, 3) small group evaluation dan 4) field test. Pada penelitian pengembangan buku digital ePub ini expert review dilakukan pada tahap implementasi untuk menentukan kelayakan produk. Setelah produk di review ahli dan dinyatakan layak, kemudian langkah selanjutnya yaitu dilakukan evaluasi. Pada penelitian ini, menggunakan evaluasi dengan 3 tahap yaitu one-to-one evaluation, small group evaluation dan field test.

Tahap one-to-one evaluation dilakukan dengan mengujicobakan produk pada tiga siswa kelas XI TKJ yang memiliki tingkat kemampuan heterogen yaitu tinggi, sedang dan rendah. Angket yang diberikan terdiri dari 15 pernyataan dengan beberapa aspek yaitu 1) Usebilitas (kegunaan), 2)Ketepatan pemilihan aplikasi, 3) Visualisasi (Tampilan) dan 4) Kelayakan Produk. Data yang diperoleh dari One-to-one Evaluation disajikan pada Tabel 2 berikut ini :

Tabel 2. Data Hasil Tahap One-to-one Evaluation

\begin{tabular}{llllll}
\hline No & Aspek Yang dinilai & Skor obs & Skor maks & $\begin{array}{l}\text { Layak } \\
\text { (\%) }\end{array}$ & Keterangan \\
$\mathbf{1}$ & Usebilitas (kegunaan) & 210 & 225 & $93 \%$ & Sangat Layak \\
$\mathbf{2}$ & Kelayakan produk & 208 & 225 & $92 \%$ & Sangat Layak \\
$\mathbf{3}$ & Ketepatan pemilihan jenis aplikasi & 202 & 225 & $89 \%$ & Sangat Layak \\
$\mathbf{4}$ & Kelayakan produk & 212 & 225 & $94 \%$ & Sangat Layak \\
\hline
\end{tabular}

Komentar / saran yang dituliskan pada angket dari ketiga siswa dapat diringkas sebagai berikut : 1) siswa menyukai buku digital ePub ini karena baru pertama kali menggunakan buku seperti ini, 2) buku digital ePub sangat menarik karena dilengkapi dengan video, 3) gambar yang terdapat pada materi ukuran font nya kurang besar.

Pada tahap small group evaluation, peneliti melibatkan 15 siswa kelas XI TKJ dengan menyebarkan angket yang terdiri dari 15 pertanyaan. Dari data hasil uji coba yang dikelompokkan berdasarkan aspek usebilitas (kegunaan), aspek ketepatan pemilihan jenis aplikasi, aspek visualisasi (tampilan) dan aspek kelayakan produk, maka diperoleh hasil persentase sebagai berikut: 1) Aspek
Usebilitas (kegunaan) 93,14 \% dengan interpretasi kelayakan "Sangat Layak", 2) Aspek Ketepatan pemilihan jenis aplikasi 95,33\% dengan interpretasi kelayakan "Sangat Layak", 3) Aspek Visualisasi (tampilan) 90,33\% dengan interpretasi kelayakan "Sangat Layak" ,4) Aspek Kelayakan produk 96\% dengan interpretasi kelayakan "Sangat Layak".

Tahap evaluasi selanjutnya yaitu field test (uji lapangan). Field test dilakukan pada 35 siswa kelas XI TKJ di SMK Negeri 1 Gempol dengan melaksanakan kegiatan pembelajaran menggunakan produk buku digital ePub. Kemudian pada akhir pembelajaran diberikan angket untuk siswa. Berikut data yang diperoleh yang disajikan pada Tabel 3 berikut ini :

Tabel 3. Data Hasil Field test

\begin{tabular}{llllll}
\hline No & Aspek Yang dinilai & Skor obs & Skor maks & Layak (\%) & $\begin{array}{l}\text { Ketera } \\
\text { ngan }\end{array}$ \\
$\mathbf{1}$ & Usebilitas (kegunaan) & 1142 & 1225 & $93 \%$ & Sangat Layak \\
$\mathbf{2}$ & Kelayakan produk & 335 & 350 & $95 \%$ & Sangat Layak \\
$\mathbf{3}$ & Ketepatan pemilihan jenis aplikasi & 631 & 700 & $90 \%$ & Sangat Layak \\
$\mathbf{4}$ & Kelayakan produk & 336 & 350 & $96 \%$ & Sangat Layak \\
\hline
\end{tabular}




\section{Analisa Hasil Uji Coba (Tryout)}

Tryout produk pada penelitian ini dilakukan dalam kegiatan pembelajaran ASJ dengan menggunakan buku digital ePub pada kelas XI TKJ di SMK Negeri $1 \mathrm{Gempol}$, dari uji coba produk tersebut terdapat hasil pembelajaran. Degeng (2018: 185) menyatakan bahwa hasil pembelajaran merupakan semua pengaruh yang dapat digunakan sebagai indikator tentang nilai dari aplikasi suatu metode di dalam kondisi yang berbeda. Klasifikasi hasil pembelajaran ada 3 yaitu keefektifan, efisiensi, dan daya tarik dalam pembelajaran. Dalam penelitian ini peneliti menggunakan salah satu klasifikasi untuk mengetahui penggunaan produk buku digital ePub sebagai bahan ajar pendamping siswa dalam proses pembelajaran. Hasil belajar siswa dapat meningkat dengan diikuti peningkatan kualitas mengajar dan kreativitas belajar (Kembuan, Rompas, Mintjelungan, Pantondate, \& Kilis, 2018).

Motivasi adalah komponen kunci dalam pembelajaran (Rufii, 2015). Ketika uji coba lapangan berlangsung, peneliti memperhatikan bahwa siswa mempunyai motivasi yang tinggi dalam mengerjakan jobsheet untuk praktikum materi Administrasi Sistem Jaringan. Tingginya motivasi siswa, mempengaruhi meningkatnya banyak keinginan siswa untuk belajar dan belajar menjadi lebih bermakna bagi mereka. (Schreglmann, 2018) juga mengemukakan bahwa individu dengan motivasi akademik yang tinggi, prestasi akademik di sektor IT akan tumbuh dan kegiatan kelas yang menerapkan teknologi informasi akan lebih bermanfaat. Pada penerapan buku digital ePub dalam pembelajaran ASJ yang dilengkapi dengan video siswa menyatakan lebih mudah dalam menyelesaikan praktikum. Karena dalam video tersebut terdapat Prosedur yang jelas agar praktikum berhasil diselesaikan dengan baik dan benar tanpa adanya trouble. Hal ini dapat dilihat dari gambar proses pembelajaran menggunakan buku digital ePub yang ditunjukkan pada gambar 5

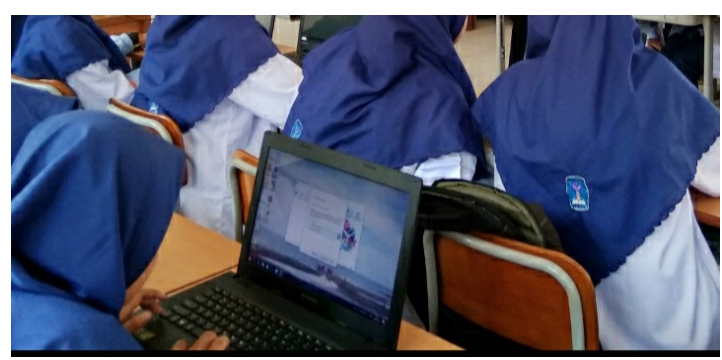

Gambar 5. Pembelajaran menggunakan buku digital $e P u b$
Fungsi media pembelajaran adalah sebagai media berkomunikasi untuk menyalurkan pesan yang dapat merangsang pikiran, perasaan, dan kemampuan sehingga mendorong proses pembelajaran menjadi lebih efektif dan efisien (Risnawati, Amir, \& Sari, 2018). Keefektifan pembelajaran dapat diukur dengan selalu mengaitkan pencapaian tujuan pembelajaran. Pencapain tujuan pembelajaran dengan menggunakan produk buku digital ePub ini dapat dilihat dari apa yang dicapai dalam pembelajaran yaitu hasil praktikum yang telah dilakukan siswa dan pembuatan laporan hasil praktikum. Hasil praktikum ini dapat dilihat dari laporan praktikum yang sudah dikumpulkan melalui link alamat google drive guru yang telah dituliskan pada menu jobsheet pada buku digital ePub. Siswa yang menyelesaikan praktikum dengan benar kemudian membuat laporan praktikum dan mengirimkan file laporan ke google drive guru. Hasil laporan praktikum yang telah diselesaikan dapat dilihat pada gambar 6

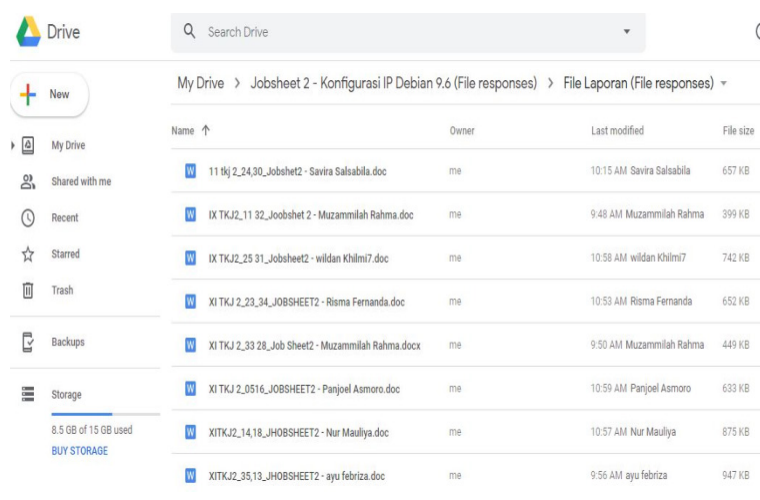

\section{Gambar 6. Laporan Hasil Praktikum di Google drive guru}

Dari google drive guru terlihat bahwa antusias siswa dalam mengerjakan praktikum mata pelajaran Administrasi Sistem Jaringan sangat baik. Beberapa aspek motivasi adalah minat, antusiasme, tanggung jawab, kesenangan dan peningkatan kinerja (Asiyah, Budiyanto, \& Tamrin, 2018). Antusias yang sangat baik dari siswa dapat dilihat dari kecepatan waktu dalam menyelesaikan praktikum hal ini juga mempengaruhi peningkatan kinerja. Pada gambar 8 terdapat waktu ketika siswa mengumpulkan laporan praktikum yaitu berkisar antara pukul 09.48 sampai 10.59. Sedangkan waktu 
untuk pembelajaran ini mempunyai waktu 6 JP (6x45 menit) sehingga waktu berakhir pembelajaran pada pukul 11.25. Namun sebagian besar siswa dapat menyelesaikan praktikum sebelum jam pelajaran berakhir.

Untuk mengumpulkan laporan hasil praktikum, peneliti memberikan alamat / link yang terdapat pada menu jobsheet. Contoh link yang diberikan yaitu $h t t p: / / g g . g g / d e b 9-6-$ Remote. Dengan mengakses alamat tersebut, siswa akan terhubung kepada Google drive guru dan dapat meng-upload hasil laporan praktikumnya. Menurut peneliti hal ini sangat efisien dalam hal pemanfaatan teknologi komunikasi dan informasi (TIK). Penggunaan aplikasi TIK dalam proses belajar mengajar, pendidikan teknik dan kejuruan artinya penggunaan TIK tersebut sudah tepat dan mendukung dalam peningkatan efisiensi dan efektivitas pembelajaran (Masran, Marian, Yunus, Rahim, \& Baser, 2017).

Dalam proses pembelajaran ketika siswa akan mengumpulkan laporan hasil praktikum dengan menggunakan USB Flashdisk. Hal ini dapat mengakibatkan laptop terinfeksi virus dari laptop lain yang antivirusnya tidak terupdate. Dan juga memerlukan waktu yang lama. Dengan menggunakan link Google drive dapat mengurangi resiko pada laptop dan lebih efisien waktu.

Produk buku digital ePub ini juga dilengkapi dengan tes evaluasi akhir pada tiap bab. Tes akhir pada tiap bab dilakukan untuk menilai pemahaman siswa terhadap materi yang dipelajari. Tes dilakukan secara online atau secara langsung menggunakan laptop maupun smartphone, hasil atau nilai tes bisa dilihat langsung oleh siswa. Pembelajaran dengan menggunakan buku digital ePub ini sangat efektif digunakan untuk mata pelajaran yang membutuhkan praktikum, khususnya pada mata pelajaran Administrasi Sistem Jaringan. Gambar dibawah ini menunjukkan bahwa siswa mengerjakan praktikum menggunakan laptop dengan melihat panduan praktikum di smartphone, sehingga lebih praktis dan siswa lebih bersemangat dalam pembelajaran. Perkembangan teknologi internet seluler yang sangat pesat, menyebabkan pembelajaran dengan menggunakan seluler menjadi cara baru untuk belajar (Chen, Dai, Luo, Zou, \& Liu, 2016).

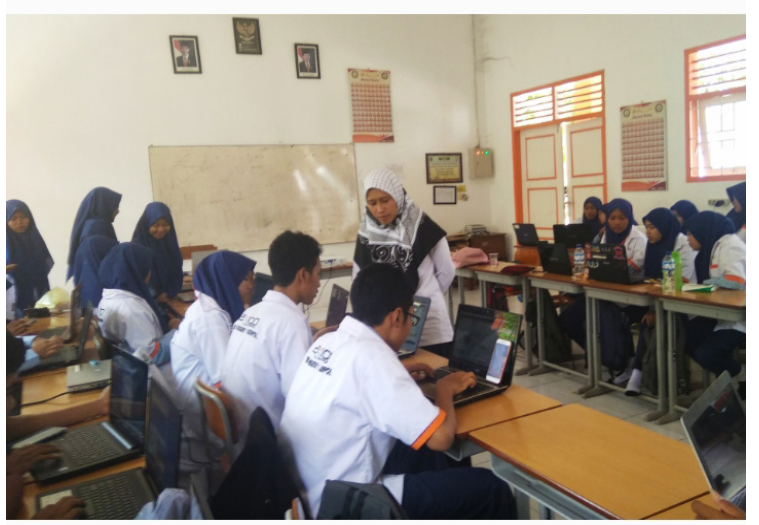

\section{Gambar 7. Pembelajaran dengan ePub}

Buku digital ePub ini dapat diakses menggunakan smartphone dan laptop. Buku digital ePub memiliki mekanisme reflow konten agar tampilan sesuai dengan perangkat yang digunakan, baik menggunakan smartphone maupun laptop (Chang \& Hung, 2018). Dan tidak membutuhkan akses internet dalam penggunaannya, dalam menggunakan semua menu bias dengan offline. Hal ini memudahkan siswa dalam belajar di kelas maupun di rumah. Sehingga apabila di saat tidak ada akses internet karena terjadi trouble maupun hal yang lainnya, pembelajaran tetap dapat berjalan lancar.

Beberapa media pembelajaran lainnyayang juga menggunakan ePub telah dikembangkan oleh para peneliti seperti pengembangan buku digital melalui aplikasi sigil (Sari, 2017), pengembangan media pembelajaran ePub mata kuliah pemrograman dasar (Rasyid, 2017), pengembangan buku elektronik (E-Book) berbasis ePub untuk kursus tampilan (Astuti \& Kusumajanto, 2017), pengembangan media pembelajaran (Aji \& Widjanarko, 2016) dan pengembangan modul digital praktikum komputer grafis 1 dalam format ePub ((Rustaman, Iqbal, \& Amelia, 2019)

Dalam mata pelajaran Administrasi Sistem Jaringan setiap materi selalu membutuhkan praktikum untuk memahami materi yang dipelajari. Pada sekolah menengah kejuruan terpadat Ujian Praktikum di akhir semester, hal ini selalu dilakukan untuk menilai siswa apakah layak untuk naik kelas atau naik tingkat. Maka dari itu praktikum sangat diperlukan dalam pembelajaran di SMK khususnya mata pelajaran produktif atau 
mata pelajaran kejuruan. Karena kemampuan dalam menyelesaikan praktikum dengan tepat sangat dibutuhkan secara pribadi oleh siswa maka produk buku digital ePub mata pelajaran Administrasi Sistem Jaringan bisa dinyatakan efektif untuk pembelajaran.

\section{SIMPULAN}

Setelah dilakukan penelitian dan pengembangan produk buku digital electronic publication (ePub) mata pelajaran Administrasi Sistem Jaringan maka dapat disimpulkan bahwa buku digital ePub ini layak untuk dimanfaatkan dalam proses pembelajaran di SMK khususnya kompetensi keahlian Teknik Komputer dan Jaringan. Maka dari itu, kedepannya, peneliti akan melakukan penyempurnaan tindak lanjut, agar kebermanfaatan media ini dapat dirasakan khalayak luas

\section{REFERENSI}

Aji, M., \& Widjanarko, D. (2016). Pengembangan Media Pembelajaran Memahami Dan Memelihara Sistem Starter Tipe Konvensional Berbasis Buku Digital Electronic Publication (EPUB). Jurnal Pendidikan Teknik Mesin Unnes, 16(1), 128007.

Anggraeni, D. M., \& Sole, F. B. (2018). E-Learning Moodle, Media Pembelajaran Fisika Abad 21. Jurnal Penelitian Dan Pengkajian IImu Pendidikan: E-Saintika, 1(2), 57-65. doi: 10.36312/e-saintika. v1i2.101

Asiyah, S., Budiyanto, C. W., \& Tamrin, A. G. (2018). Technology Acceptance Model in the Analysis of the Influence of E-Learning Implementation to Students' Motivation. IJIE (Indonesian Journal of Informatics Education), 2(1), 51. doi: 10.20961/ijie.v2i1.14496

Astuti, O. W., \& Kusumajanto, D. D. (2017). Development of Electronic Book (E-Book) EPUB-Based for Display Course. Jurnal Pendidikan Bisnis Dan Manajemen, 3(2), 157-164. doi: 10.17977/um003v3i22017p157

Bau, S., Sunardi, M., \& Sudiyanto, M. (2017). Development of E-BookBased Discovery Learning to Improve
Motivation and Learning Outcomes on Accounting Education University of Flores East Nusa Tenggara. doi: 10.2991/ictte-17.2017.73

Bhattacharjee, B., \& Deb, K. (2016). Role of ICT in 21 st Century's Teacher Education. International Journal of Education and Information Studies, 6(1), 1-6.

Chang, H. P., \& Hung, J. C. (2018). Comparison of the features of EPUB e-book and SCORM e-learning content model. International Journal of Distance Education Technologies, 16(2), 1-17. doi: 10.4018/IJDET.2018040101

Chen, M., Dai, M., Luo, H., Zou, X., \& Liu, S. (2016). Design and Implementation of an Android EPUB3.0 eBook Learning System. doi: 10.2991/ icmmita-16.2016.226

Darma, R. S., Setyadi, A., Wilujeng, I., Jumadi, \& Kuswanto, H. (2019). Multimedia Learning Module Development based on SIGIL Software in Physics Learning. Journal of Physics: Conference Series, 1233(1). doi: 10.1088/17426596/1233/1/012042

Figueiredo, M., Bidarra, J., \& Bostad, R. (2016). The development of an ebook for teaching and learning mathematics. Lecture Notes in Computer Science (Including Subseries Lecture Notes in Artificial Intelligence and Lecture Notes in Bioinformatics), 9739, 49-56. doi: 10.1007/978-3-319-40238-3 5

Irum, S., Munshi, P., Bhatti, T., \& Awan, J. H. (2018). University Teachers knowledge about technological devices and their use: An Analytical study. International Journal of Computer Science and Network Security, 18(8), 74-80.

Kembuan, D. R. E., Rompas, P. T. D., Mintjelungan, M., Pantondate, T., \& Kilis, B. M. H. (2018). Teaching Quality and Learning Creativity in Technical and Vocational Schools. IOP Conference Series: Materials Science and Engineering, 306(1). doi: 10.1088/1757$899 X / 306 / 1 / 012028$

Kurt, S. (2017). ADDIE Model: Instructional Design. doi: 10.1017/ CBO9781107415324.004 
Mardiyah, M., Mustaji, M., \& Sitompul, N. (2019). Meningkatkan Keterampilan Writing Of Narrative Text Dengan Menggunakan Teaching Materials. Edcomtech Jurnal Kajian Teknologi Pendidikan, 4(2), 89-95. doi: 10.17977/ um039v4i22019p089

Masran, S. H., Marian, M. F., Yunus, F. A. N., Rahim, M. B., \& Baser, J. A. (2017). Effectiveness of using an interactive media in teaching and learning: A case study. Proceedings of the 2017 IEEE 9th International Conference on Engineering Education, IEEE ICEED 2017, 2018-Janua, 222-227. doi: 10.1109/ ICEED.2017.8251197

Ningsih, S., \& Adesti, A. (2019). Pengembangan Mobile Learning Berbasis Android pada Mata Kuliah Strategi Pembelajaran Universitas Baturaja. Edcomtech, (2), 163-172.

Purba, K. R., Liliana, \& Runtulalu, D. (2017). Development of interactive learning media for simulating human digestive system. Proceedings - 2017 International Conference on Soft Computing, Intelligent System and Information Technology: Building Intelligence Through IOT and Big Data, ICSIIT 2017, 2018-Janua, 270-274. doi: 10.1109/ICSIIT.2017.67

Purnamawati, P., Arfandi, A., \& Nurfaeda, N. (2019). The level of use of information and communication technology at vocational high school. Jurnal Pendidikan Vokasi, 9(3), 249-257. doi: 10.21831/jpv.v9i3.27117

Risnawati, Amir, Z., \& Sari, N. (2018). The development of learning media based on visual, auditory, and kinesthetic (VAK) approach to facilitate students' mathematical understanding ability. Journal of Physics: Conference Series, 1028(1). doi: 10.1088/17426596/1028/1/012129

Rufii, R. (2015). Developing Module on Constructivist Learning Strategies to Promote Students' Independence and Performance. International Journal of Education, 7(1), 18. doi: 10.5296/ije. v7i1.6675
Rustaman, A. H., Iqbal, M., \& Amelia, W. (2019). Pengembangan Modul Digital Praktikum Komputer Grafis 1 Dalam Format Elektonik Publication (EPUB) Untuk Meningkatkan Pemahaman Teknik Grafis Mahasiswa Desain Komunikasi Visual (Topik: Digital Imaging). Jurnal Ilmu Sosial Dan Pendidikan, 3(1), 224-229.

Sari, A. S. (2017). Pengembangan Buku Digital Melalui Aplikasi Sigil Pada Mata Kuliah Cookies Dan Candys. Jurnal Science Tech, 3(2), 46-54.

SchregImann, S. (2018). Developing Academic Motivation Scale for Learning Information Technology (AMSLIT): A Study of Validity and Reliability. Journal of Education and Learning, 7(4), 145. doi: 10.5539/jel.v7n4p145

Surahman, E., Sulthoni, S., Ulfa, S., Husna, A., Ramdiana, H., Thaariq, Z. Z. A., ... Qolbi, M. S. (2020). Pelatihan Micro Learning Object Berbasis TPACK bagi Guru-Guru SMA di Garut. Abdimas Pedagogi: Jurnal IImiah Pengabdian Kepada Masyarakat, 3(1), 1-14.

Syaimar, C. P., \& Sutiarso, S. (2017). Pengembangan media pembelajaran berbasis mobile dalam meningkatkan motivasi dan kemampuan matematis siswa. Prosiding \{Seminar\} \{Nasional\} \{Matematika\} Dan \{Pendidikan\} \{Matematika\}, 1, 5.

Vinu, P. V., Sherimon, P. C., \& Krishnan, R. (2011). Towards pervasive mobile learning-The vision of 21 st century. Procedia - Social and Behavioral Sciences, 15, 3067-3073. doi: 10.1016/j. sbspro.2011.04.247

Wardani, M., Rufi'i, R., \& Harwanto, H. (2019). The Effect Of Ict-Based Learning On Students' Learning Achievement Of Computer System In Vocational High School. Edcomtech Jurnal Kajian Teknologi Pendidikan, 4(1), 27-37. doi: 10.17977/um039v4i12019p027 